\title{
Key questions in marine megafauna movement ecology
}

Graeme C. Hays ${ }^{1 *}$, Luciana C. Ferreira ${ }^{2,3}$, Ana M.M. Sequeira², Mark G. Meekan², Carlos M. Duarte ${ }^{4}$, Helen Bailey ${ }^{5}$, Fred Bailleul ${ }^{6}$, W. Don Bowen ${ }^{7}$, M. Julian Caley ${ }^{8,9}$, Daniel P. Costa ${ }^{10}$, Victor M. Eguíluz ${ }^{11}$, Sabrina Fossette ${ }^{12}$, Ari S. Friedlaender ${ }^{13}$, Nick Gales $^{14}$, Adrian C. Gleiss ${ }^{15}$, John Gunn ${ }^{9}$, Rob Harcourt ${ }^{16}$, Elliott L. Hazen ${ }^{17}$, Michael R. Heithaus ${ }^{18}$, Michelle Heupel ${ }^{9,19}$, Kim Holland ${ }^{20}{ }^{\text {, Markus Horning }}{ }^{21}$, Ian Jonsen ${ }^{16}$, Gerald L. Kooyman ${ }^{22}$, Christopher G. Lowe ${ }^{23}$, Peter T. Madsen ${ }^{24,25}$, Helene Marsh ${ }^{26}$, Richard A. Phillips ${ }^{27}$, David Righton ${ }^{28}$, Yan Ropert-Coudert ${ }^{29}$, Katsufumi Sato ${ }^{30}$, Scott A. Shaffer ${ }^{31}$, Colin A. Simpfendorfer ${ }^{19}$, David W. Sims ${ }^{32,33,34}$, Gregory Skomal $^{35}$, Akinori Takahashi ${ }^{36}$, Philip N. Trathan ${ }^{27}$, Martin Wikelski ${ }^{37,39}$, Jamie N. Womble $^{39}$, Michele Thums ${ }^{3}$

${ }^{1}$ Centre for Integrative Ecology, Deakin University (Warrnambool Campus), Geelong, Victoria, Australia ${ }^{2}$ IOMRC and The UWA Oceans Institute, School of Animal Biology and Centre for Marine Futures, The University of Western Australia, Crawley, Western Australia, Australia ${ }^{3}$ Australian Institute of Marine Science, c/o The UWA Oceans Institute, University of Western Australia, 35 Stirling Highway, Crawley WA 6009, Australia

${ }^{4}$ King Abdullah University of Science and Technology (KAUST), Red Sea Research Center (RSRC), Thuwal, 23955-6900, Saudi Arabia

${ }^{5}$ Chesapeake Biological Laboratory, University of Maryland Center for Environmental Science, Solomons, Maryland 20688, USA

${ }^{6}$ South Australian Research and Development Institute (Aquatic Sciences), 2 Hamra Avenue, West Beach, Adelaide, SA, 5024, Australia

${ }^{7}$ Population Ecology Division, Bedford Institute of Oceanography, Dartmouth, Nova Scotia, B2Y 4A2, Canada

${ }^{8}$ Australian Research Council Centre of Excellence for Mathematical and Statistical Frontiers ${ }^{9}$ Australian Institute of Marine Science, PMB No. 3, Townsville, QLD 4810, Australia.

${ }^{10}$ Department of Ecology and Evolutionary Biology, University of California, Santa Cruz, CA 95060, USA

${ }^{11}$ Instituto de Física Interdisciplinar y Sistemas Complejos IFISC (CSIC-UIB), E-07122 Palma de Mallorca, Spain

${ }^{12}$ School of Animal Biology, University of Western Australia, 35 Stirling Highway, Crawley, WA 6009, Australia

${ }^{13}$ Department of Fisheries and Wildlife, Marine Mammal Institute, Oregon State University, 2030 Marine Science Drive, Newport, OR 97365, USA

${ }^{14}$ Australian Antarctic Division, Department of the Environment, Australian Government, Kingston, Australia 
${ }^{15}$ Centre for Fish \& Fisheries Research, School of Veterinary \& Life Sciences, Murdoch University, 90 South Street, Murdoch, Western Australia 6150, Australia ${ }^{16}$ Department of Biological Sciences, Macquarie University, Sydney, NSW 2109 Australia ${ }^{17}$ Environmental Research Division, Southwest Fisheries Science Center, National Oceanic and Atmospheric Administration, 99 Pacific St. Suite 255A, Monterey, CA, 93940 USA 18 Department of Biological Sciences, Florida International University, Miami, Florida 33174, USA

${ }^{19}$ Centre for Sustainable Tropical Fisheries and Aquaculture \& College of Marine and Environmental Sciences, James Cook University, Townsville, Qld Australia 4811

${ }^{20}$ Hawaii Institute of Marine Biology, University of Hawaii at Manoa, PO Box 1346, Kaneohe Hawaii 98744, USA

${ }^{21}$ Science Department, Alaska SeaLife Center, Seward, AK 99664, USA

${ }^{22}$ Scripps Inst. of Oceanography, Univ. of California San Diego, San Diego, CA, USA

${ }^{23}$ Dept. of Biological Sciences, Calif. State Univ. Long Beach, Long Beach, CA 90840, USA

${ }^{24}$ Zoophysiology, Department of Bioscience, Aarhus University, Aarhus DK 8000, Denmark

${ }^{25}$ Murdoch University Cetacean Research Unit, School of Veterinary and Life Sciences, Murdoch University, Perth, Australia

${ }^{26}$ College of Marine and Environmental Science, James Cook University, Townsville Qld 4810 Australia

${ }^{27}$ British Antarctic Survey, Natural Environment Research Council, Cambridge, UK

${ }^{28}$ Fisheries and Ecosystems Division, Cefas Laboratory, Pakefield Road, Lowestoft, Suffolk, NR34 7RU, UK

${ }^{29}$ Centre d'Etudes Biologiques de Chizé, Station d'Écologie de Chizé-Université de La Rochelle CNRS UMR 7372, 79360 Villiers-en-Bois, France

${ }^{30}$ Atmosphere and Ocean Research Institute, The University of Tokyo 5-1-5 Kashiwanoha, Kashiwa City, Chiba Prefecture, 277-8564, Japan

${ }^{31}$ Department of Biological Sciences, San Jose State University, San Jose CA 95192-0100

${ }^{32}$ Marine Biological Association of the United Kingdom, The Laboratory, Citadel Hill, Plymouth PL1 2PB, UK

${ }^{33}$ Ocean and Earth Science, National Oceanography Centre Southampton, University of Southampton, Waterfront Campus, European Way, Southampton SO14 3ZH, UK

${ }^{34}$ Centre for Biological Sciences, Building 85, University of Southampton, Highfield Campus, Southampton SO17 1BJ, UK

${ }^{35}$ Massachusetts Shark Research Project, Division of Marine Fisheries, 1213 Purchase St., New Bedford, MA 02740, USA

${ }^{36}$ National Institute of Polar Research, Tachikawa, Tokyo 190-8518, Japan

${ }^{37}$ Department of Migration and ImmunoEcology, Max-Planck Institute for Ornithology, Am Obstberg 1, 78315 Radolfzell, Germany

${ }^{38}$ Konstanz University, Dept. of Biology, 78457 Konstanz, Germany

${ }^{39}$ National Park Service, Glacier Bay Field Station, 3100 National Park Road, Juneau, Alaska 99801 USA

*Correspondence: g.hays@deakin.edu.au (G.C. Hays) 


\section{Glossary}

Bio-logging: the use of miniaturized animal-attached tags for logging or transmission of data about an animal's movements, behaviour, physiology or their environment. The term often refers to marine species.

Biotelemetry: the remote transmission of data from electronic tags attached to animals that provide for example, information on movement, behaviour, physiology and the environment. We use the term here synonymously with bio-logging, which also encompasses data stored on tags attached to animals that must be recovered for download.

Marine megafauna: Large animals living in the sea including mammals, reptiles, large fishes and seabirds.

Movement ecology: As a part of ecology, animal movement is a research field which is dedicated to understanding patterns, drivers, physiology and consequences of animal movement such as seasonal migration, dispersal and foraging.

It is a golden age for animal movement studies and so an opportune time to assess priorities for future work. We assembled 40 experts to identify key questions in this field, focusing on marine megafauna, which include a broad range of birds, mammals, reptiles and fish. Research on these taxa has both underpinned many of the recent technical developments and led to fundamental discoveries in the field. We show that the questions have broad applicability to other taxa including terrestrial animals, flying insects and swimming invertebrates and, as such, this exercise provides a useful roadmap for targeted deployments and data syntheses that should advance the field of movement ecology.

The advent of a range of small, reliable data-loggers and transmitters that can record horizontal and vertical movements, physiology and reproductive biology has led to many new, amazing insights into the ecology of taxa ranging from insects to whales [1,2] (Figure 1). For example, we are now able to track and record the physiological state of animals as they travel across entire ocean basins or continents, fly over the highest mountains or dive from the surface to the ocean depths [3-6]. These types of studies have addressed holistic questions encompassing cross-taxa comparisons in both terrestrial and marine systems that have investigated how animals optimize their locomotion [7]; their search patterns for prey [8] and the factors that constrain their migration distances [9], dive performance [10] and swimming speed [11] (Figure 2).

The deployment of tracking devices, especially for extended periods, can impact the wellbeing of equipped animals $[12,13]$ and tags and deployment efforts can also be very costly. 
For these reasons, there is an urgent need to triage the most important fundamental and applied questions in the field of movement ecology for targeted research, particularly in the case of marine species for which technical advances in tagging have been profound. To this end, we assembled 40 leading experts in the field of bio-logging of marine megafauna to identify key questions. We illustrate how many of these questions not only apply to these taxa but also to terrestrial vertebrates and other animal groups including mobile invertebrates in both terrestrial and marine environments. Our objective was to focus the agenda for the field of movement ecology in an informed way that encompassed both fundamental questions of high interest and priority questions that have more direct impact on management and conservation.

\section{Materials and methods}

We followed a similar protocol used previously [14] of identifying leading experts in the field and soliciting their views on key questions in a selected area. The process began with a meeting organized in Perth (17 - 21 November 2014), where experts in the area of bio-logging of marine megafauna were invited from across Australia and international institutions. These experts were selected based on their publications and extent of work in this area. The 15 experts who attended this meeting were then each asked to select other individuals from around the world who should be invited to participate in this process. We targeted researchers working in the area of the movement of marine megafauna and also the broader conservation community, including government and non-government conservation agencies (e.g. IUCN, NOAA). The extended list of experts were then each asked to supply up to 10 key questions to advance the field of the movement ecology of marine megafauna, including taxa such as cetaceans, elasmobranchs, pinnipeds, large teleosts (tunas, billfishes etc.), sirenians, seabirds and marine reptiles (e.g. turtles). Responses were compiled and similar questions were grouped, along with the associated votes, into a single question. The full list was then distributed and participants were asked to vote on their top ten questions and confirm that they were satisfied with the rearticulation of questions. The votes were tallied and a final list of key questions was circulated and agreed upon. This final list of questions is described below in the text, boxes and figures.

\section{Results}

HOW CAN MOVEMENT DATA BE USED TO SUPPORT CONSERVATION AND MANAGEMENT ? A justification for many tracking studies is that knowledge about the movements of animals might help inform conservation management $[15,16]$ and, indeed, there are good examples of how data can be used in this way. For example, in the Antarctic, the world's first Marine Protected Area located entirely in the High Seas was partly justified by the movements of Adélie penguins (Pygoscelis adeliae) during their energy intensive pre-moult period [17], while in the Pacific Ocean, turtle telemetry data have been used to create habitat models based on ocean conditions, reducing bycatch through dynamic ocean management [18]. Similarly movement data have shown how often migratory birds are not protected along large portions of their migration routes [19]. However, incorporation of movement data into conservation 
strategies remains under-utilized. Tracking data can potentially help designate the location, size and timing of conservation zones and test their efficacy. Movement data can also aid stock assessments, identification of stock boundaries for species of conservation concern, ecosystembased management and management of highly migratory species.

\section{ARE THERE SIMPLE RULES UNDERLYING SEEMINGLY COMPLEX MOVEMENT PATTERNS AND HENCE COMMON DRIVERS FOR MOVEMENT ACROSS SPECIES?}

Common patterns of search behaviour by marine predators have been demonstrated across sharks, bony fish, turtles and seabirds, which move in spatial patterns that can be approximated by a theoretically optimal search pattern known as a truncated Lévy walk $[8,20]$. The observed patterns of movement are theoretically optimal for locating the patchy and sparse distributions of prey that occur in the ocean [8]. Although a truncated Lévy walk and other simple null models are convenient for testing commonalities in movement among taxonomically wellseparated species (see also Figure 1), there is a need for future research aimed at understanding the physiological and behavioural mechanisms underpinning common movement patterns [11], their evolutionary origin [21] and the costs and benefits of different patterns (Box 1). As a corollary, addressing this question of commonalities will also shed light on the levels and drivers of variation in vertical and horizontal movements (Figure 2).

\section{HOW DOES LEARNING AND MEMORY VERSUS INNATE BEHAVIOURS INFLUENCE MOVEMENT} PATTERNS INCLUDING ONTOGENETIC CHANGES?

Relatively little is known about the effects of learning and memory on the movement patterns of marine megafauna. Scale-free patterns of movement suggest that some marine megafauna search for prey probabilistically without prior knowledge of prey distribution [8], but it is likely that they rely on learning and memory to some extent to move and forage efficiently [22,23]. The effects of learning and memory are often inferred from foraging site fidelity, but quantifying those effects remains challenging $[16,24]$. Identification of innate behaviours is equally problematic because of the difficulty of finding "naive" individuals $[25,26]$. Tracking studies of juveniles are relatively infrequent compared to those of adults (often called 'lostyears') especially in sea turtles, seabirds and some marine mammals, because tag recovery is more difficult and the size of tags is often less suitable for juveniles [27].

\section{TO WHAT DEGREE DO SOCIAL INTERACTIONS INFLUENCE MOVEMENTS ?}

Many species occur in social groups during both short-term (hours-weeks), mesoscale (km$100 \mathrm{~s} \mathrm{~km}$ ) movements (e.g., foraging or refuging) and during long distance (1000s km) migrations. In several species of marine mammals there appears to be coordination during feeding events, and marine birds are attracted to other feeding individuals [28,29]. For many, successful orientation along migration routes might potentially require naive animals to follow experienced individuals or reflect the transfer of navigational information among individuals. In all these scenarios, how individuals within these aggregations influence the behaviour of the 
larger group is poorly understood because generally only a few focal individuals are tracked. However, breakthroughs in both hardware and analysis tools show promise for elucidating social interactions [e.g. 30,31].

\section{HOW DOES THE DISTRIBUTION OF PREY IMPACT MOVEMENT ?}

Only in relatively few cases has the prey field around a forager been measured directly, yet this is probably a fundamental driver of movement patterns [32,33]. Animals encountering prey are likely to react by slowing down and increasing their turning rate, behaviours thought to increase their encounter rate with prey. Well documented examples show how the diel diving patterns of animals are linked to the diel vertical migration patterns of their prey and consequently there is debate about whether movement patterns are simply an emerging property from a forager interacting with the prey field. This debate is further fuelled by the finding that movement patterns for the same individual can vary across different habitats that likely have different prey distributions [20]. Moreover, diving behaviour, in particular, is unlikely to be driven by environmental drivers, but ecosystem features, such as depth layers, e.g. the deep scattering layer, offering an abundance of prey [34]. Future studies will need to assess, with more rigour, the fine-scale distribution of prey while animals are being tracked.

\section{WHAT SENSORY INFORMATION DO ANIMALS USE TO SENSE PREY, BREEDING PARTNERS AND ENVIRONMENTAL CONDITIONS?}

Recent technological advances have allowed for increasingly detailed insights into marine animal sensing in the wild. Movement data can shed light on the sensory information used to navigate during migration (Box 2). Light levels from down-welling light and bioluminescent prey have recently been recorded with on-board tags [35] that, along with camera tags, offer insights into how visual cues guide behaviour. Intriguing advances have been made with sound recording tags that have uncovered how echo information guides prey capture movement in cetaceans [36]. While the function of individual sensory systems can now be studied in detail, a challenge to overcome is that animals might rely on complex multimodal sensing to inform behavioural changes to find and intercept prey, choose breeding partners and navigate (Box 2).

\section{CAN MOVEMENT DATA PROVIDE INFORMATION ON THE ECOSYSTEM ROLE OF MARINE MEGAFAUNA ?}

Marine megafauna can play important roles in ecosystems through both top-down processes (as predators and herbivores) [37] and bottom-up processes including the redistribution of nutrients [38]. Key to understanding these ecological roles are analyses of spatiotemporal patterns of abundance and behaviours (e.g. foraging, resting), which are driven by movement decisions. For example, dolphins foraging offshore can move nutrients into nearshore waters where they rest [39], whales migrating from high latitudes could translocate nutrients to oligotrophic tropical systems [38]), and juvenile bull sharks (Carcharhinus leucas) can move 
nutrients upstream in estuaries through commuting behaviour [40]. Yet there has been little use of movement data in this context.

\section{HOW MUCH DOES THE PHYSICAL ENVIRONMENT INFLUENCE MOVEMENT?}

Permanent (e.g. bathymetry) and ephemeral abiotic factors (e.g. temperature, salinity, dissolved oxygen) are thought to strongly influence movements [41]. These factors can interact directly with the physiology of megafauna, especially ectotherms, or indirectly via the physiology of their prey [42] across temporal scales ranging from hours to decades. The physical structure of the water column also acts to accumulate both megafauna and prey through oceanographic features ranging from thermoclines (10-100 m), eddies and upwelling zones (10$100 \mathrm{~km})$, to boundary currents $(1000 \mathrm{~km})$ [6]. Disentangling the direct effects of the physical environment on the movement and behaviour of megafauna from indirect effects on their prey remains a significant challenge [43].

\section{HOW WILL CLIMATE CHANGE IMPACT ANIMAL MOVEMENTS?}

Climate change, including extreme events such as storms, El Niño phenomena and warm water anomalies are likely to increase in frequency and might impact the movements and phenology of large marine megafauna by changing the broad-scale distribution and composition of prey as well as other resources (e.g. suitable water temperature, resting and breeding substrate) [4447]. Migration patterns of marine megafauna will likely change to be more poleward with warming [48], although the complex effects of biotic interactions and habitat availability, for example, can lead to counter-intuitive re-distribution patterns in some taxa [49]. Some animals, including pinnipeds and penguins, might be particularly sensitive to large-scale environmental changes when they are tied to land- or ice-based breeding colonies and hence have limited ability to shift their foraging locations [50]. Similarly, the rapid loss of Arctic sea ice might affect the movement patterns of Arctic megafauna, restricting those of animals, such as the polar bear and the walrus using sea ice as a platform, and enhancing ones whose access to the Arctic had been precluded by sea ice. The complexities of the drivers of animal movements make predictions of climate change impacts difficult [51].

\section{HOW CAN RISKS, CONSEQUENCES AND BENEFITS OF BIO-LOGGING AT THE LEVEL OF INDIVIDUALS AND POPULATIONS BE EVALUATED?}

Attaching or implanting devices to streamlined animals comes with great responsibility. While guidelines and reviews are regularly produced [52,53], the ethical dimensions of the risks associated with capturing and instrumenting an animal need to be constantly reinforced within the scientific community and must be quantified [12]. There are technical challenges to quantifying such risks, as often the absence of 'true' controls hampers our ability to determine what component(s) of the biology of the animal is most affected. Our ability to do this is, however, paramount to the conduct of future experiments. Consequently, scientists have a responsibility to behave ethically and to remind the public that they constantly balance the 
impact of scientific investigations with the necessity to collect data of utmost importance to the understanding of the biology of a given species and its subsequent conservation. Reducing the impacts of devices will remain an ongoing priority as will carefully defining the required sample size (Box 3).

HOW DO WE INTEGRATE PHYSIOLOGICAL CONTEXT INTO TAGGING STUDIES TO GAIN A MORE SYNOPTIC PICTURE OF MOVEMENT AND BEHAVIOUR?

Although there have been distinct challenges in studying physiology of free-living animals, new non-lethal physiological sampling techniques (muscle biopsy, blood and exhalant), bio-logging and telemetry sensors have allowed a better understanding of behavioural responses to broad ranging physical conditions such as water temperature and dissolved oxygen concentrations $[10,54]$. Unfortunately, many of these physiological measures only provide a brief snapshot of the animals' physiological state prior or subsequent to the tracking of their movements. In many cases there remains a distinct lack of information on physiological constraints of species movements and how animals will physiologically and behaviourally respond to changing environmental conditions.

\section{WHAT ARE THE MAJOR DRIVERS OF LONG DISTANCE MOVEMENTS ?}

Long distance (1000s $\mathrm{km}$ ) directed movements have now been documented in a broad range of marine megafauna. Resources that vary in quality in space and time are often thought to be the fundamental driver for these movements [55]. For example, suitable conditions for breeding and foraging might be found in different areas and so necessitate reproductive migrations or sometimes animals might move seasonally to track favourable foraging conditions $[6,42]$. Maximum migration distances generally scale with body size and also vary with taxa and mode of locomotion (Figure 2) and are thought to reflect fuel stores and cost of transport. However the specifics of how animals select their destinations for these directed movements and what drives their timing, plasticity and variability across individuals are much more enigmatic as are the roles of learning versus innate behaviours. In some cases migrations are initiated when conditions aid travel, such as tail winds for some birds and insects, and currents for some fish. [56]. Comparisons between terrestrial bird and marine predator migrations can inform our understanding of processes directing targeted movements.

\section{HOW DOES PREDATION RISK INFLUENCE MOVEMENT STRATEGIES ?}

The risk of predation can have profound impacts. For example, risk from sharks is associated with foraging habitat shifts by dolphins, sea turtles, sirenians, and seabirds [57](Figure 3). These studies echo those in terrestrial systems and with invertebrates, where the role of predators in shaping animal movements is well defined $[58,59]$. Much work remains to be done. Failure to explicitly consider predation risk in movement studies could lead to erroneous conclusions, for example mistaking refuging areas for dense prey patches. Further, how do we measure the lack of behaviour when an animal does not do something because of the predation risk associated 
with that behaviour? Future studies of the role of how predation risk shapes movement are important in light of declines in truly apex predatory species and the potential for predation risk to induce marine trophic cascades [60]. Furthermore, like predators, pathogens can also shape movement patterns in insects and birds [61] and might have this same impact in some marine taxa.

WHAT AREAS CAN BE CONSIDERED HOTSPOTS FOR MULTIPLE SPECIES ON A GLOBAL SCALE ? Collation of individual telemetry datasets into large, multi-species databases that are linked to other sources of relevant data, such as survey data, is central to revealing general patterns in movement behaviour and to highlight hotspots for multiple species. The potential of such effort in amassing tracking datasets has been highlighted [42]. The current challenge is, therefore, to develop this approach across a wider range of species and ecosystems, as this could reveal collective, emergent patterns of movement behaviour and allow identification of multispecies hotspots at a worldwide scale. To achieve this, a large partnership akin to the size of that of BirdLife International (the world's largest partnership of bird conservation organisations), is needed. In turn, the identification of such hotspots will help inform current approaches increasingly used to assist systematic marine spatial planning such as the Convention on Biological Diversity's Ecological or Biologically Significant Areas, the International Maritime Organisation's Particularly Sensitive Sea Areas, IUCN's Key Biodiversity Areas, and Biologically Important Areas (adopted by the USA and Australia).

\section{HOW DO ANTHROPOGENIC ACTIVITIES (E.G. SHIPPING, FISHING, WATER MANAGEMENT) AFFECT MOVEMENTS?}

Many human activities pose serious threats to the ecology of marine megafauna. For example, fishing and shipping can kill or injure animals, while industrial development (oil and gas extraction, offshore wind farms), pollution (plastic, chemical wastes, runoff, noise) and space use (vessel activity, aquaculture production) can affect megafauna through the disruption of natural behaviours and alteration of habitat [62]. The extent to which interactions with anthropogenic threats ultimately determine the behaviour, survival and fitness of megafauna is largely unknown. However, the description of movement patterns can provide data essential for the identification and mitigation of potential impacts. For example, tracking data has revealed that blue whales (Balaenoptera musculus) have limited ability to avoid collisions with ships [63] and that small shifts in traffic routes could reduce the risk of ship-strike [64]. The description of movement patterns in situations and at times when marine megafauna are exposed to potential threats from anthropogenic activities must be a key goal for research that seeks to optimise strategies for the management, conservation and resilience of this fauna $[48,65]$.

\section{Concluding remarks}


Many of the questions we identify here apply equally to other taxa including terrestrial vertebrates, insects and marine invertebrates. For example, the use of movement data to inform conservation also applies to many terrestrial vertebrates [66,67]; understanding how animals orientate and navigate is relevant to movements of jellyfish, flying insects and birds $[68,69]$; examination of how social interactions impact movement is applicable to studies of pigeons [70]; and assessing how the physical environment shapes movement is relevant to studies of a range of terrestrial herbivores [71]. As such our questions likely provide a solid roadmap for the general field of animal biotelemetry.

Progress will sometimes need further development of cross-discipline collaborations. For example, the last few years have shown the immense value of collaborations among ecologists, mathematicians, physicists, oceanographers, engineers and information technologists to identify general patterns in animal movement $[8,42,72,73]$. Additionally, increasing engagement with policy makers will help translate tracking data into real world conservation benefits. Step-changes in the duration that individuals are tracked for might be needed to address ontogenetic changes in movements, the roles of learnt versus innate behaviours and the consequences of movement to the fitness of individuals. However, the tracking of individuals for longer periods needs to be pursued with consideration of the ethical concerns of the impact of very long deployments in some species. In this regard, some species might be more appropriate models for tackling particular questions than others. Long-term studies, albeit not necessarily tracking the same individuals over time, will also be needed to assess climate change impacts and impacts of extreme events.

While technological developments have facilitated many of the major discoveries of marine animal movement and the Argos satellite tracking system remains integral to remote data relay $[2,74]$, some key questions also point to the need for further developments. For example, tracking early life-stages might require increasing miniaturization of tags and new techniques might need to be developed for some groups that remain hard to track for long periods because they are not readily accessible or live in habitats where direct radio reception is not possible (e.g. the deep sea or underground). The end-point of tracking data can reveal important information about the fate of that tracked animal. For example, bio-logging data in animals as diverse as raptors and eels can provide evidence that individuals have died $[75,76]$ and so tags might therefore be able to assess mortality rates through space and time $[77,78]$ as is commonly done for terrestrial species using tags equipped with mortality switches [79].

Variability in movement patterns across a range of scales of time and space is a pervading theme across tracking studies, yet the sources of this variation often remain obscure. For example, within the same population, some individuals can show reproductive migrations spanning $1000 \mathrm{~s}$ of $\mathrm{km}$ while others remain in the vicinity of their breeding grounds all the time [80]. An overarching understanding of this individual variability remains elusive and will need consideration of a range of other issues such as the role of predators in constraining prey species' movements. It is important to highlight that a broad range of taxa, including swimming marine species and flying animals such as birds and insects, are subjected to flows of the environment be they swimmers subjected to currents or flyers subjected to winds. The impact of flows can be important, with the movement of tracked individuals reflecting the summation 
of that individual's movement plus the wind or current vector. Disentangling an animal's active movement from movement due to environmental flows remains a challenge [69]. In theory, tracked animals might be used to assess local flows [81]: for example, if an animal's ground track is recorded, while at the same time its orientation and movement speed is logged so that its movement vector can be calculated, then the difference between the ground track and the movement vector equals the advection due to the environmental flow, be it current or wind. While the questions posed above reflect a consensus on priorities among experts in the field, we acknowledge that consensus is but one pathway to scientific breakthroughs. Other exciting prospects for marine animal tracking include an improved understanding of the marine ecosystem by complementing the random or stratified designs that characterize oceanographic surveys with the more targeted guidance provided by the animal's perception of the environment, developed over millions of years of evolution. As animal-based platforms are increasingly loaded with environmental sensors, animal tracking might help solve fundamental questions in oceanography, particularly in challenging and under-sampled environments, such as the polar oceans and the deep sea.

We conducted this horizon-scanning exercise to help drive the field of marine animal movement ecology forward through the identification of key questions. Although we do not claim that the list of questions is exhaustive, we believe that it captures many of the key issues and challenges facing this field of research and can provide a roadmap for the future.

\section{Author contributions}

GCH conceived the study at a workshop organized by MT, AMMS, MM, VME and CMD. GCH assembled the questions with help from LCF, MT, AMMS and MM. All authors submitted questions and voted on the assembled questions. GCH wrote the manuscript with WDB, YRC, ELH, MM, AMMS, DWS, AT, LCF, MT, PNT, PTM. All authors commented on drafts. Workshop funding was granted to MT and AMMS by the UWA Oceans Institute, the Australian Institute of Marine Science, and the Office of Sponsored Research at King Abdullah University of Science and Technology (KAUST).

\section{REFERENCES}

1. Kays, R. et al. (2015) Terrestrial animal tracking as an eye on life and planet. Science 348, aaa2478

2. Hussey, N.E. et al. (2015) Aquatic animal telemetry: A panoramic window into the underwater world. Science 348, 1255642

3. Bishop, C.M. et al. (2015) The roller coaster flight strategy of bar-headed geese conserves energy during Himalayan migrations. Science 347, 250-254

4. McDonald, B.I. and Ponganis, P.J. (2013) Insights from venous oxygen profiles: oxygen utilization and management in diving California sea lions. J. Exp. Biol. 216, 3332-3341

5. Ponganis, P.J. et al. (2011). In pursuit of Irving and Scholander: a review of oxygen store management in seals and penguins. J. Exp. Biol. 214, 3325-3339

6. Shaffer, S.A. et al. (2006) Migratory shearwaters integrate oceanic resources across the Pacific Ocean in an endless summer. Proc. Natl. Acad. Sci. U.S.A. 103, 12799-12802 
7. Gleiss, A.C. et al. (2011) Convergent evolution in locomotory patterns of flying and swimming animals. Nat. Commun. 2, e352

8. Sims, D.W. et al. (2008) Scaling laws of marine predator search behaviour. Nature 451, 10981102

9. Hein, A.M. et al. (2011) Energetic and biomechanical constraints on animal migration distance. Ecol. Lett. 15, 104-110

10. Horning, M. (2012) Constraint lines and performance envelopes in behavioral physiology: the case of the aerobic dive limit. Front. Physiol. 3, 381

11. Watanabe, Y.Y. et al. (2015) Comparative analyses of animal-tracking data reveal ecological significance of endothermy in fishes. Proc. Natl Acad. Sci. U.S.A. 112, 6104-6109

12. Jones, T.T. et al. (2013) Calculating the ecological impacts of animal-borne instruments on aquatic organisms. Methods Ecol. Evol. 4, 1178-1186

13. Maresh, J.L. et al. (2015) Summing the strokes: energy economy in northern elephant seals during large scale foraging migrations. Mov. Ecol. 3, 22

14. Sutherland, W.J. et al. (2013). Identification of 100 fundamental ecological questions. J. Ecol. 101, 58-67

15. Cooke S.J. (2008) Biotelemetry and biologging in endangered species research and animal conservation: relevance to regional, national and IUCN Red List threat assessments. Endanger. Species Res. 4, 165-185

16. Costa D.P. et al. (2012) New insights into pelagic migrations: Implications for ecology and conservation. Annu. Rev. Ecol. Evol. Syst. 43, 73-96

17. CCAMLR (2009) Commission for the Conservation of Antarctic Marine Living Resources, Report of the twenty-eighth Meeting of the Commission. Hobart, Australia, 203

18. Lewison, R. et al. (2015) Dynamic ocean management: identifying the critical ingredients of dynamic approaches to ocean resource management. BioScience 65, 486-498

19. Runge, C.A. et al. (2015) Protected areas and global conservation of migratory birds. Science 350, 1255-1258

20. Humphries, N.E. et al. (2010) Environmental context explains Lévy and Brownian movement patterns of marine predators. Nature 465, 1066-1069

21. Sims, D.W. et al. (2014) Hierarchical random walks in trace fossils and the origin of optimal search behaviour. Proc. Natl. Acad. Sci. U.S.A. 111, 11073-11078

22. Regular, P.M. et al. (2013) Must marine predators always follow scaling laws? Memory guides the foraging decisions of a pursuit-diving seabird. Anim. Behav. 86(3), 545-552

23. Scott, R. et al. (2014) Ontogeny of long distance migration. Ecology 95, 2840-2850

24. Fagan, W.F. et al. (2013) Spatial memory and animal movement. Ecol. Lett. 16(10), 13161329

25. Heupel, M.R. et al. (2012) Consistent movement traits indicative of innate behavior in neonate sharks. J. Exp. Mar. Biol. Ecol. 432, 131-137

26. McConnell, B. et al. (2002) Movements and foraging areas of naive, recently weaned southern elephant seal pups. J. Anim. Ecol. 71, 65-78

27. Riotte-Lambert, L. and Weimerskirch, H. (2013) Do naive juvenile seabirds forage differently from adults? Proc. R. Soc. B 280, 20131434 
28. Gales, N.J. et al. (2004) Do crabeater seals forage cooperatively? Deep-Sea Res. // 51, 23052310

29. Sigler, M.F. et al. (2004) Availability to Steller sea lions of a seasonal prey resource: a prespawning aggregation of eulachon. Can. J. Fish. Aquat. Sci. 61, 1475-1484

30. Lidgard, D.C. et al. (2012) Animal-borne acoustic transceivers reveal patterns of at-sea associations in an upper-trophic level predator. PLOS ONE 7, 1-8

31. Hooker, S.K. et al. (2015) Images as proximity sensors: the incidence of conspecific foraging in Antarctic fur seals. Anim. Biotelem. 3, 37

32. Womble, J.N. et al. (2014) Linking marine predator diving behavior to local prey fields in contrasting habitats in a subarctic glacial fjord. Mar. Biol. 161, 1361-1374

33. Goldbogen, J.A. et al. (2015) Prey density and distribution drive the three-dimensional foraging strategies of the largest filter feeder. Funct. Ecol. 29, 951-961

34. Irigoien, X. et al. (2014). Large mesopelagic fishes biomass and trophic efficiency in the open ocean. Nature Commun. 5, 3271

35. Vacquie-Garcia, J. et al. (2012) Foraging in the darkness of the Southern Ocean: Influence of bioluminescence on a deep diving predator. PLOS ONE 7, e43565

36. Madsen P.T. et al. (2013) Echolocation in Blainville's beaked whales (Mesoplodon densirostris). J. Comp. Physiol. A 199, 451-469

37. Atwood, T.B. et al. (2015) Predators help protect carbon stocks in blue carbon ecosystems. Nat. Clim. Change 5, 1038-1045

38. Roman, J. et al. (2014) Whales as marine ecosystem engineers. Front. Ecol. Environ. 12, 377385

39. Norris, K.S. and Dohl, T.P. (1980) Behavior of the Hawaiian spinner dolphin, Stenella longirostris. Fish. Bull. 77, 821-849

40. Matich, P. et al. (2011) Contrasting patterns of individual specialization and trophic coupling in two marine apex predators. J. Anim. Ecol. 80, 294-305

41. Heithaus, M.R. et al. (2009) Physical factors influencing the distribution of a top predator in a subtropical oligotrophic estuary. Limnol. Oceanogr. 54, 472-482

42. Block, B.A. et al. (2011) Tracking apex marine predator movements in a dynamic ocean. Nature 475, 86-90

43. Ropert-Coudert, Y. et al. (2009) Impact of small-scale environmental perturbations on local marine food resources: a case study of a predator, the little penguin. Proc. R. Soc. B 276, 4105-4109

44. Afan, I. et al. (2015) A novel spatio-temporal scale based on ocean currents unravels environmental drivers of reproductive timing in a marine predator. Proc. R. Soc. B 282, 20150721

45. Udyawer, V. et al. (2013) Variable response of coastal sharks to severe tropical storms: environmental cues and changes in space use. Mar. Ecol. Prog. Ser. 480, 171-183

46. Marsh, H. et al. (2012) The ecology and conservation of Sirenia: dugongs and manatees. Cambridge University Press

47. Verges, A. et al. (2014) The tropicalisation of temperate marine ecosystems: climatemediated changes in herbivory and community phase shifts. Proc. R. Soc. B 281, 20140846 
48. Sequeira, A.M.M. et al. (2014) Predicting current and future global distributions of whale sharks. Global Change Biol. 20, 778-789

49. Rutterford, L.A et al. (2015) Future fish distributions constrained by depth in warming seas. Nat. Clim. Change 5, 569-573

50. Bost C.A. et al. (2015) Large-scale climatic anomalies affect marine predator foraging behaviour and demography. Nature Commun. 6, 8220

51. Hazen, E.L. et al. (2013) Predicted habitat shifts of Pacific top predators in a changing climate. Nat. Clim. Change 3, 234-238

52. Brown, R.S. et al. (2011) An introduction to the practical and ethical perspectives on the need to advance and standardize the intracoelomic surgical implantation of electronic tags in fish. Rev. Fish. Bio. Fish. 21, 1-9

53. Field, I.C. et al. (2012) Refining instrument attachment on phocid seals. Mar. Mam. Sci. 28, 325-332

54. Hunt, K.E. et al. (2013) Overcoming the challenges of studying conservation physiology in large whales: a review on available methods. Conserv. Physiol. 1, 1-24

55. Alerstam, T. et al. (2003) Long-distance migration: evolution and determinants. Oikos 103, 247-260

56. Chapman, J.W. et al. (2011) Animal orientation strategies for movement in flows. Curr. Biol. 21, 861-870

57. Heithaus, M.R. et al. (2012) The ecological importance of intact top predator populations: a synthesis of 15 years of research in a seagrass ecosystem. Mar. Freshwater Res. 63, 10391050

58. Brown, J.S. and Kotler, B.P. (2004) Hazardous duty pay and the foraging cost of predation. Ecol. Lett. 7, 999-1014

59. Hays, G.C. et al. (2001) Individual variability in diel migration of a marine copepod: why some individuals remain at depth while others migrate. Limnol. Oceanogr. 46, 2050-2054

60. Burkholder, D.A. et al. (2013) Patterns of top-down control in a seagrass ecosystem: could a roving apex predator (Galeocerdo cuvier) induce a behavior-mediated trophic cascade? J. Anim. Ecol. 82, 1192-1202

61. Chapman, J.W. et al. (2015) Long-range seasonal migration in insects: mechanisms, evolutionary drivers and ecological consequences. Ecol. Lett. 18, 287-302

62. Lewison, R.L. et al. (2014) Global patterns of marine mammal, seabird, and sea turtle bycatch reveal taxa-specific and cumulative megafauna hotspots. Proc. Natl. Acad. Sci. U.S.A. 111, 5271-5276

63. McKenna, M.F. et al. (2015) Simultaneous tracking of blue whales and large ships demonstrates limited behavioral responses for avoiding collision. Endanger. Species Res. 27, 219-232

64. Irvine, L.M. et al. (2014) Spatial and temporal occurrence of blue whales off the U.S. West Coast, with implications for management. PLoS ONE 9, e102959

65. Trathan, P.N. et al. (2015) Pollution, habitat loss, fishing, and climate change as critical threats to penguins. Conserv. Biol. 29, 31-41 
66. Wall, J. et al. (2014) Novel opportunities for wildlife conservation and research with realtime monitoring. Ecol. Appl. 24, 593-601

67. Williams, T.M. et al. (2014) Instantaneous energetics of puma kills reveal advantage of felid sneak attacks. Science 346, 81-85

68. Fossette, S. et al. (2015) Current-Oriented swimming by jellyfish and its role in bloom maintenance. Curr. Biol. 25, 342-347

69. Chapman, J.W. et al. (2011) Detection of flow direction in high-flying insect and songbird migrants. Curr. Biol. 25, 751-752.

70. Nagy, M. et al. (2010) Hierarchical group dynamics in pigeon flocks. Nature 464, 890-893

71. Mosser, A.A. et al. (2014) Towards an energetic landscape: broad-scale accelerometry in woodland caribou. J. Anim. Ecol. 83, 916-922

72. Jonsen, I.D. et al. (2005) Robust state-space modeling of animal movement data. Ecology $86,2874-2880$

73. Raymond, B. et al. (2015) Important marine habitat off east Antarctica revealed by two decades of multi-species predator tracking. Ecography 38, 121-129

74. Holland, K.N et al. (2014) Use of land-based Argos receiving stations to improve data collection from satellite tagged marine animals. In: The 5th International Bio-logging Science Symposium. Strasbourg, France.

75. Klaassen, R.H.G. et al. (2014) When and where does mortality occur in migratory birds? Direct evidence from long- term satellite tracking of raptors. J. Anim. Ecol. 83, 176-184

76. Wahlberg, M. et al. (2014) Evidence of marine mammal predation of the European eel (Anguilla anguilla L.) on its marine migration. Deep-Sea Res. I 86, 32-38

77. Horning, M. and Mellish, J.E. (2014) In cold blood: evidence of Pacific sleeper shark (Somniosus pacificus) predation on Steller sea lions (Eumetopias jubatus) in the Gulf of Alaska. Fish. Bull. 112, 297-310

78. Heupel, M.R. and Simpfendorfer, C.A. (2002) Estimation of mortality of juvenile blacktip sharks, Carcharhinus limbatus, within a nursery area based on telemetry data. Can. J. Fish. Aquat. Sci. 59, 624-632

79. Winder, V.L. et al. (2014) Effects of wind energy development on survival of female greater prairie-chickens. J. Appl. Ecol. 51, 395-405

80. Womble, J.N. and Gende, S.M. (2013) Post-breeding season migrations of a top predator, the harbor seal, from a marine protected area in Alaska. PLoS ONE 8, e55386.

81. Treep, J. et al. (2015) Using high resolution GPS tracking data of bird flight for meteorological observations. Bull. Amer. Meteor. Soc. doi:10.1175/BAMS-D-14-00234.1

82. Hays, G.C. and Scott, R. (2013) Global patterns for upper ceilings on migration distance in sea turtles and comparisons with fish, birds and mammals. Funct. Ecol. 27, 748-756

83. Bastille-Rousseau, G. et al. (2015) Unveiling trade-offs in resource selection of migratory caribou using a mechanistic movement model of availability. Ecography 38, 1049-1059.

84. Halsey, L.G. et al. (2009) The relationship between oxygen consumption and body acceleration in a range of species. Comp. Biochem. Physiol. A 152, 197-202 
85. Volpov, B.L. et al. (2015) Validating the relationship between 3-dimensional body acceleration and oxygen consumption in trained Steller sea lions. J. Comp. Physiol. B 185, 695-708

86. Watanabe Y.Y. and Takahashi, A. (2013) Linking animal-borne video to accelerometers reveals prey capture variability. Proc. Natl. Acad. Sci. U.S.A. 110, 2199-2204

87. Adachi, T. et al. (2014) The foraging benefits of being fat in a highly migratory marine mammal. Proc. R. Soc. B 281, 20142120

88. Biuw, M. et al. (2007) Variations in behavior and condition of a Southern Ocean top predator in relation to in situ oceanographic conditions. Proc. Natl. Acad. Sci. U.S.A. 104, 13705-13710

89. Darwin, C (1873) Perception in the lower animals. Nature 7, 360

90. Lohmann K.J. et al. (2008) Goal navigation and island-finding in sea turtles. J. Exp. Mar. Biol. Ecol. 356, 83-95

91. Gagliardo, A. et al. (2013) Oceanic navigation in Cory's shearwaters: evidence for a crucial role of olfactory cues for homing after displacement. J. Exp. Biol. 216, 2798-2805

92. Reynolds, A.M. et al. (2015). Pelagic seabird flight patterns are consistent with a reliance on olfactory maps for oceanic navigation. Proc. R. Soc. B 282, 20150468

93. Hays, G.C. et al. (2014) Route optimisation and solving Zermelo's navigation problem during long distance migration in cross flows. Ecol. Lett. 17, 137-143

94. Fossette, S. et al. (2014) Pan-Atlantic analysis of the overlap of a highly migratory species, the leatherback turtle, with pelagic longline fisheries. Proc. R. Soc. B 281, 20133065

95. Hebblewhite, M. and Haydon, D.T. (2010) Distinguishing technology from biology: a critical review of the use of GPS telemetry data in ecology. Philos. Trans. R. Soc. London. [Biol] 365, 2303-2312

96. Lindberg, M.S. and Walker, J. (2007) Satellite Telemetry in Avian Research and Management: Sample Size Considerations. J. Wildl. Manage. 71, 1002-1009

97. Chapman, D.D. et al. (2015) There and back again: A review of residency and return migrations in sharks, with Implications for population structure and management. Annu. Rev. Mar. Sci. 7, 547-570

98. Ferreira, L.C. et al. (2015) Crossing latitudes-long-distance tracking of an apex predator. PLOS ONE 10, e0116916

99. Hindell, M.A. et al. (2015) Circumpolar habitat use in the southern elephant seal: implications for foraging success and population trajectories. Ecosphere, In Press.

100. Roquet, F. et al. (2014). A Southern Indian Ocean database of hydrographic profiles obtained with instrumented elephant seals. Scientific Data 1:140028. 


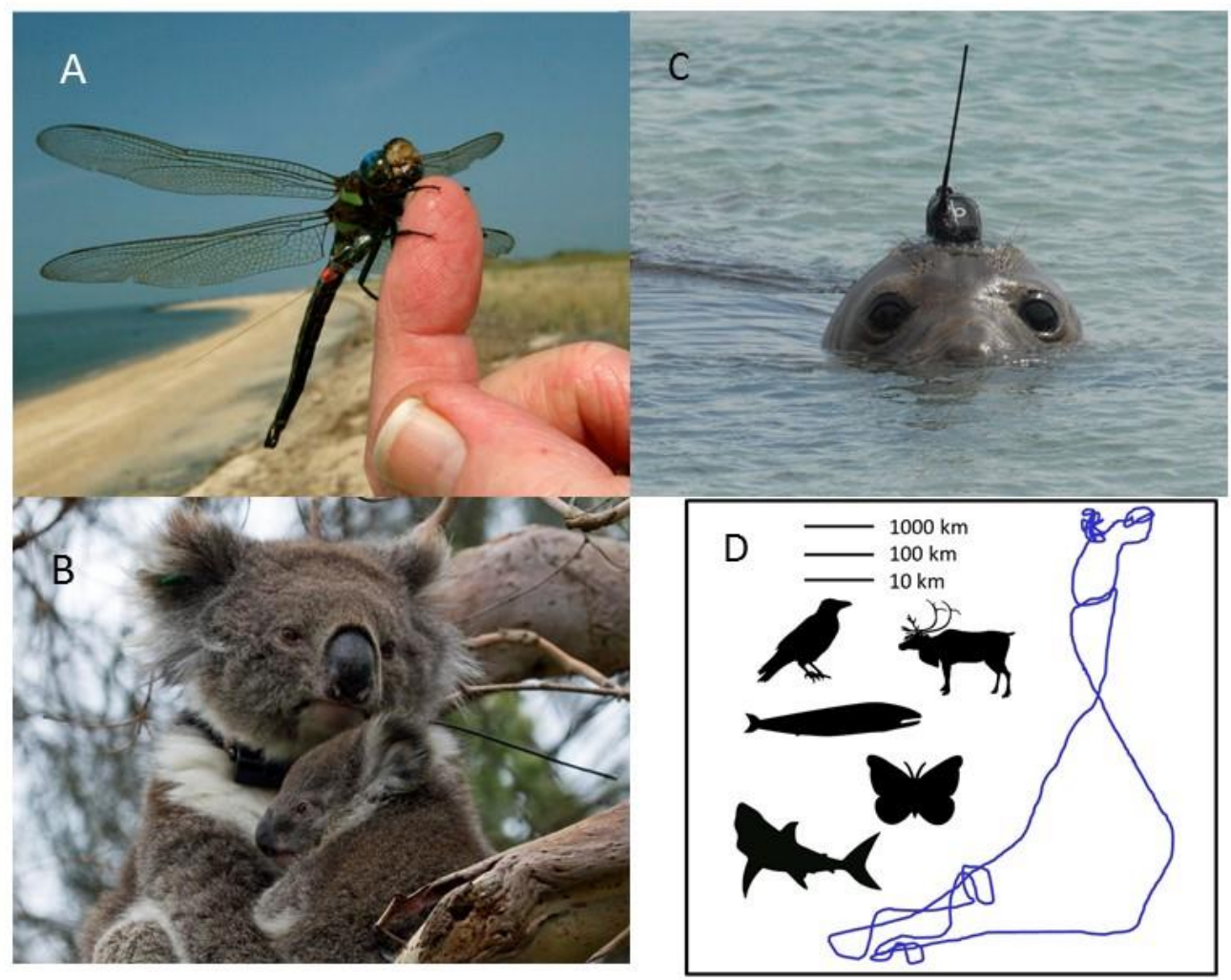

Figure. 1. Commonalities across species, habitats and spatial scales. Like other mobile animals, marine megafauna move through their environment to obtain resources such as prey, breeding grounds and mates (and in the case of divers they surface to obtain air) and so movement patterns profoundly impact fitness. Marine megafauna can be tracked, in high resolution, as they move in both horizontal and vertical dimensions. As a corollary, invertebrates including crawling, flying and swimming taxa as well as a broad range of terrestrial species can likewise be tracked. (A-C) a dragonfly (Anax junius), a koala (Phascolarctos cinereus) and a northern elephant seal (Mirounga angustirostris) each equipped with a tracking tag (credits: Martin Wikelski, Dan Costa, Desley Whisson). The small size of tags, to reduce impacts on behaviour, means they are difficult to see in (A) and (B). (D) Spatial scale of movement. Movement patterns can be examined across taxa and habitats and over scales from a few $\mathrm{cm}$ to 10,000 s of $\mathrm{km}$, illustrated schematically here. Across this breadth of studies, many common questions exists such as whether general 'rules' might underpin complex movements, the roles of learning, navigation cues employed, the role of predators and prey distribution in shaping movements and how climate change might impact movements. This track could equally be from a broad range of taxa that walk, fly or swim and any of the scale bars might apply. In this case, it is the track of a shearwater (Puffinus griseus) flying the length of Pacific [6]. 

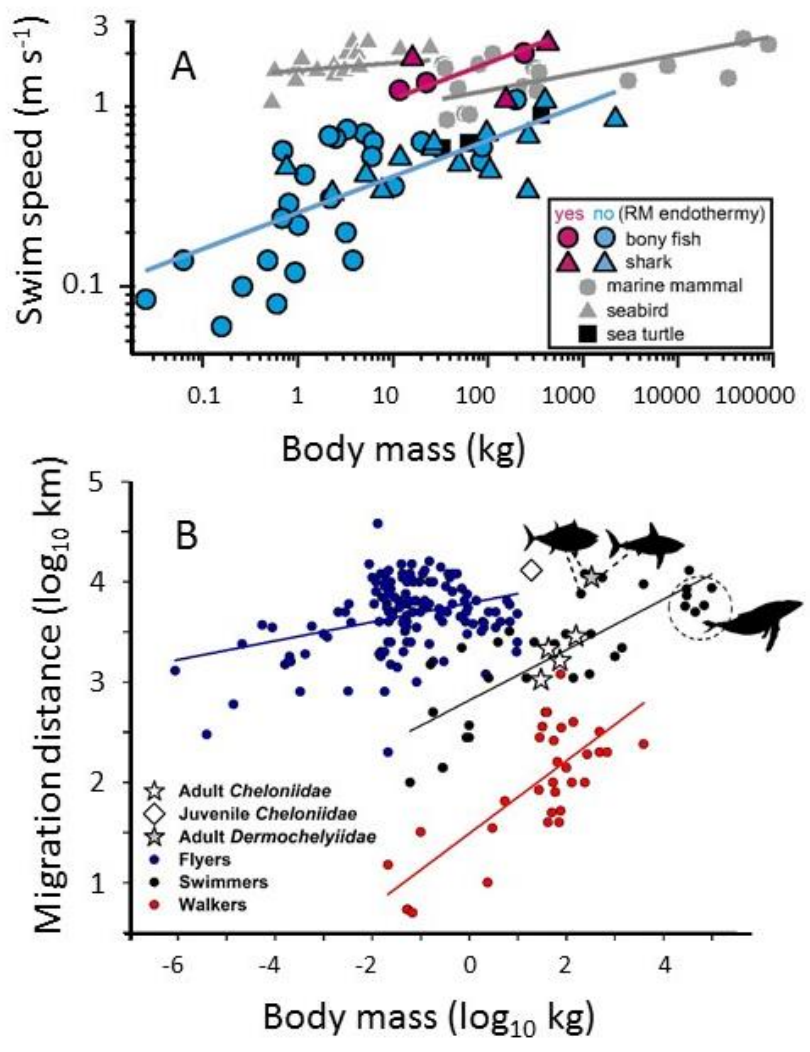

Figure 2. The value of comparisons across taxa. Tracking data from a range of taxa can be used to address overarching questions of movement and ecology. (A) Comparison of different swimmers reveals the roles of body size and endothermy versus ectothermy in influencing cruising swim speed [11]. (B) Comparison across walkers, flyers and swimmers shows the roles of body size and gait in driving maximum migration distances [82]. 

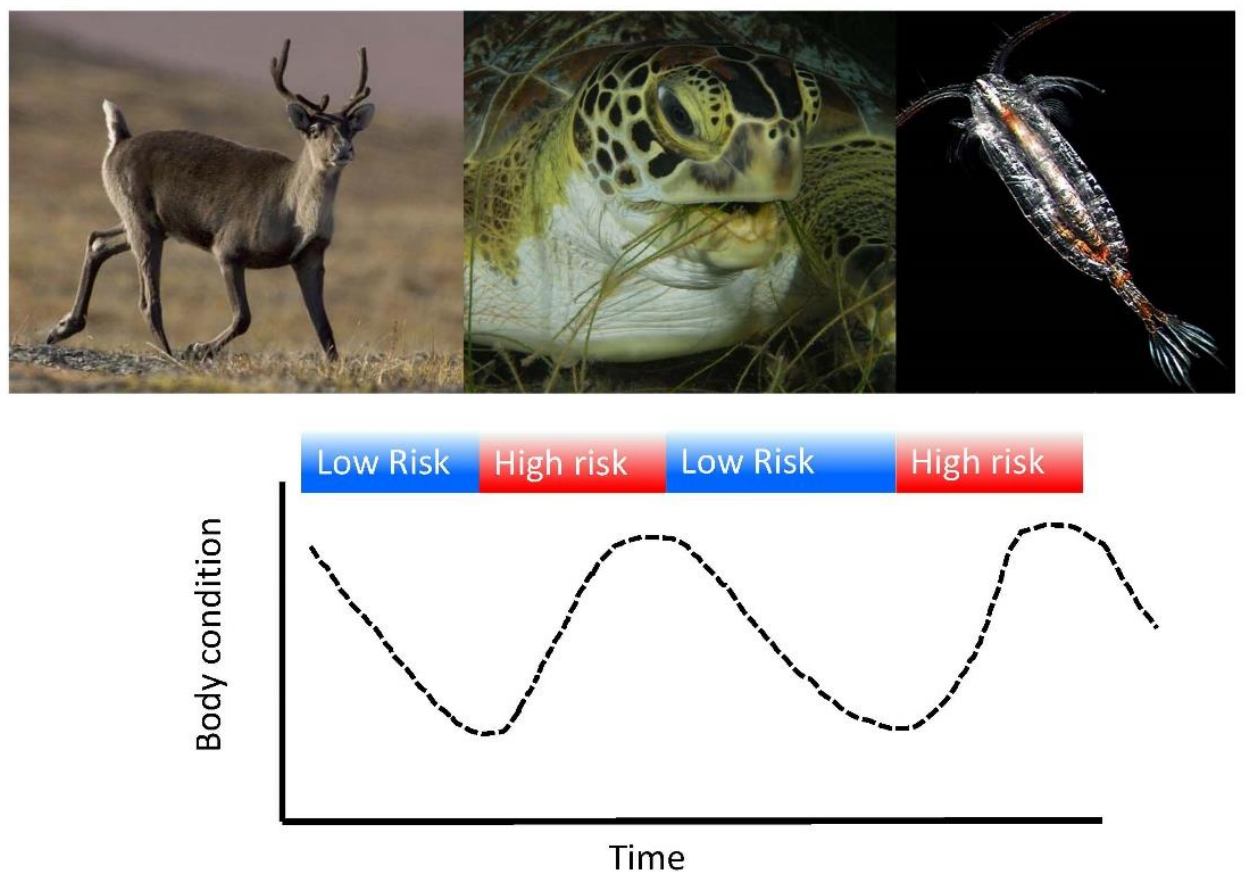

Figure 3. Role of predators in shaping movements. Across terrestrial, freshwater and marine habitats, recording animal movements shows that the risk of predation can have a profound impact on animal movements with individuals balancing predation risk with foraging success from fine-scale habitat selection to migratory patterns. How individuals solve the food-risk trade-off can vary with attributes of individuals. Caribou (Rangifer tarandus) (top left panel) movements during calving are orientated to areas with abundant forage and lower risk of predation from black bears (Ursus americanus)[83]. Green turtles (Chelonia mydas) (top middle panel) balance foraging gain with risk of predation from tiger sharks in shallow sea grass pastures by selecting habitats relative to their body condition [57]. A calanoid copepod (top right panel) showing a lipid sac used for energy storage. Many species of marine copepod show daily vertical movements ascending to shallow depth to feed at night when their risk of predation is lower [59]. Lower panel: Across systems, the use of high risk areas can be driven by body condition: with animals in poor condition more likely to run the risk of predation and use areas with great food availability. Understanding such behaviour is critical in light of changes to both food availability and predation risk in oceans and other ecosystems. High resolution tracking in relation to habitat quality might reveal these trade-offs. These movements have profound implications for the vertical and horizontal movements of many marine megafauna (credits: Russell Hopcroft, RD and BS Kirkby). 


\section{BOX 1. WHAT ARE THE COSTS AND BENEFITS OF DIFFERENT MOVEMENT PATTERNS ?}

A central pillar of ecology is assessing the costs and benefits of various behaviours. This applies equally to movement studies where a challenge is to measure costs and benefits over various scales: from the energy expenditure and prey capture probability of an individual prey pursuit event, up to the cost and benefit of large scale migration. Quantifying the metabolic costs of movement patterns remains a challenge and is central to assessing the cost and benefits of various movement patterns. For example, doubly labelled water can be used for approximating metabolic rate, but generally only provides an integrated value over hours or days and is not feasible for fishes due to high water turnover rates. Laboratory measurements of metabolic rate can be extrapolated to free-living animals, or predicted for large taxa based on allometric scaling relationships, but only with caution. Energy expenditure derived from accelerometer data shows great promise for estimating the metabolic rate of free-living animals by providing a robust measure of activity (e.g. [84] but see [85]) allowing various models of optimal movement to be tested [7].

Sensors available to record energy intake include those measuring the physiological state of the digestive tract (e.g. stomach or oesophageal temperature), those measuring the mechanical movement of the head and/or jaws, animal-attached cameras allowing direct observations of prey capture and audio recorders to record the sound or echoes of prey capture [86]. The quantification of benefits of different movement strategies however remains a challenge. Most studies so far have focused on temporally isolated events, such as the structure of a single dive or foraging trip. The benefits associated with larger scale and/or longterm movements (e.g. transit versus area restricted search) remain elusive, due to the generally limited recording duration of data-loggers (but see [87] for instance). Despite the growing toolkit of bio-logging instruments, linking the benefits of observed movement strategies to ecological and evolutionary relevant scales (e.g., reproductive success, survival, lifetime reproductive output) remains a grand challenge, although there are model systems that allow fitness benefits to be directly measured. For example, in some cases tracked animals return to provision offspring or to nest (e.g. seabirds, turtles) so that the implications of their previous movements can be assessed in terms of their weight change, reproductive investment and survival across many years. Additionally it might sometimes be possible to assess changes in their body condition by remotely relayed data as in the case, for example, of buoyancy changes in elephant seals that are related to body fat levels [88].

\section{Box 2. HOW DO ANIMALS NAVIGATE AND ORIENTATE IN THE OPEN SEA?}

Tracking animals can shed light on both their navigational performance and hint at the underlying cues employed and so help tackle long standing questions of broad interest that have perplexed scientists for $>100$ years [89]. One approach to identify the cues used in movements is through laboratory trials where the available information (e.g. geomagnetic cues, light, wave movements) is manipulated [90]. This approach has been used, for example, with monarch butterflies, passerine birds and hatchling sea turtles. However, tracking animals can potentially reveal information about their navigational ability. At-sea experiments have been 
performed, such as temporarily attaching magnets or making animals anosmic and then tracking individuals [91], although typically inferences of navigational cues are made from animals behaving naturally. Across both marine birds and sea turtles, the directed approach to islands from downwind suggests the use of wind-borne odours in island and/or prey finding [92]. Many taxa, from a range of habitats, including bees, birds, seals and turtles likely have good cognitive maps of their home area, but can still navigate to distant remote areas using cues such as the geomagnetic maps. For example, direct tracking has shown that sea turtles can travel many 1000s of $\mathrm{km}$ between breeding and foraging grounds, have fidelity to both, but do not pin-point these targets following direct routes and can sometimes struggle to find remote targets such as small islands [93]. These tracks point to a fairly crude map sense in the open ocean, a conclusion supporting laboratory evidence of broad-scale geomagnetic markers [90]. As with terrestrial birds and insects, it remains a challenge to acquire detailed information about environmental flows (winds and currents) so that the roles of active movement and passive advection can be teased apart [69].

\section{BOX 3. OBSERVATIONAL DESIGN AND INFERENCE - HOW MANY TAGS ARE ENOUGH ?}

There is no simple answer to this question, but rather the type of information obtained changes as sample sizes increases. For example, tracking one individual can reveal the extent of movement in hitherto unknown detail, tracking a handful of individuals can start to reveal individual variability, while tracking 30+ individuals can reveal how populations behave [94]. Tracking individuals from a population across many years can start to reveal climate change impacts. The issue of sample size is fundamental to good experimental design and populationlevel inference in movement studies. Approaches using satellite telemetry can be particularly vulnerable to small sample sizes as the high cost of tags restricts the number that can be deployed (see [95] for a review). For studies that aim to assess spatial and temporal distributions, simulated GPS data suggest that $>20$ tagged individuals are a minimum sample size $[80,96]$, with greater numbers required where movement patterns must be categorized by sex, age, geography and time period. Furthermore, in species such as marine predators, there are often individual specializations in movement patterns $[6,97,98)$. Such within-species variation combined with the ongoing decline in science funding means that few studies have the resources to collect the sample sizes needed to characterize movement patterns of whole populations. Two approaches might overcome these problems. Firstly, collaborative studies that combine efforts to increase sample sizes to create synoptic views of individual and multispecies movement patterns $[42,73,99]$. Secondly, the development of global, freely available databases to facilitate data sharing in animal movement ecology $[1,2,100]$. These approaches will be key to achieving the sample sizes required for population-level inference and ultimately to move towards an understanding of the emergent properties of multiple species and ecosystems. 


\section{Trends}

Technical advances make this an exciting time for animal movement studies with a range of small, reliable data-loggers and transmitters that can record horizontal and vertical movements as well as aspects of physiology and reproductive biology.

40 experts identify key questions in the field of movement ecology.

Questions have broad applicability across species, habitats and spatial scales and will apply to animals in both marine and terrestrial habitats as well as both vertebrates and invertebrates, including birds, mammals, reptiles, fish, insects and plankton.

\section{Outstanding questions}

Understanding general 'rules' underpinning complex movements, the roles of learning, navigation cues employed, the role of predators and prey distribution in shaping movements, levels and drivers of variation in vertical and horizontal movements and how climate change might impact movements.

Collaborations among ecologists, mathematicians, physicists, oceanographers, engineers and information technologists will help tackle key questions and increasing engagement with policy makers will help translate tracking data into real world conservation benefits.

Increasing miniaturization of tags will allow early life-stages to be tracked and development of new techniques may be needed for some groups that remain hard to track. Across studies the tracking of individuals needs to be pursued with consideration of the ethical concerns of the impact of deployments.

Collation of individual telemetry datasets into large, multi-species databases linked to other sources of relevant data (e.g. environmental) will help reveal general patterns in movement and highlight hotspots. 